\section{Novel RYR1 genetic mutation with variable expressivity within a family}

\author{
Swathi Beladakere Ramaswamy, MD; Randall \\ Schwartz, MD; Sachin M. Bhagavan, MD; Raghav \\ Govindarajan, MD
}

University of Missouri, Columbia, Missouri

\section{ABSTRACT}

The ryanodine receptor (RYRl) gene encodes ryanodine receptor, a calcium channel in the sarcoplasmic reticulum. In active state it releases $\mathrm{Ca} 2+$ from the sarcoplasmic reticulum leading to muscle contraction. Variants in RYRI mutation are associated with the majority of cases of malignant hyperthermia (MH) and exertion heat illness. These mutations are also considered one of the causes of inherited myopathies. There is a wide spectrum of genotypic, phenotypic and histopathological presentation of various mutations of this gene. Also, families with the same mutation showcase variable phenotype and severity of phenotype as seen in this case of a 45-year-old male and his children with novel heterogeneous missense mutationK1393R, pLysl393Arg (AAG $>$ AGG): c4178A $>$ G in exon 29 of RYRl. The phenotypic variability captured in this family is exertion heat intolerance, exertional urticaria, weakness of muscles of limbs and swallowing and delayed motor milestones in the younger generation. This sheds light on the occurrence of wide phenotypic variability including varying severity of phenotypes with the same gene mutation within the family and across families.

\section{Introduction}

Mutations in the skeletal muscle ryanodine receptor (RYRl) gene have emerged as a cause of inherited neuromuscular disease, ranging from various congenital myopathies and malignant hyperthermia (MH) susceptibility trait with or without associated weakness to exertional myalgia/heat illness with or without rhabdomyolysis. Approximately 200 missense variants in RYRl have been described ${ }^{1,2,3}$. RYRl-related myopathies are genetically, histopathologically, and clinically more diverse than previously considered. RYRl-related myopathies may manifest throughout life, with a wide range from early-onset myopathies to rhabdomyolysis triggered by various stimuli in otherwise healthy individuals.

Recent studies have also shown the presence of wide spectrum RYRl mutation and their novel clinical presentations. Exertion myalgia, exertion heat illness, heat stroke, and asymptomatic elevated creatinine kinase levels are some alternative presentations ${ }^{1}$.

The objective of this case is to report one such novel mutation in RYRl gene [heterogeneous missense mutationK1393R, pLysl393Arg (AAG>AGG): c4178A>G in exon 29 of RYR1] in a family who shows variable expressivity among generations within the family and presents with variable phenotypes like exertional heat intolerance and exertional urticaria along with the well-known phenotype of muscle weakness.

\section{Case Report}

A 45-year-old male presented with progressive lower limb weakness and generalized fatigue for the last 5 years. He had initially noticed such weakness when getting up from the floor while playing with his children. He also had shortness of breath on climbing three flights of stairs. He has a history of recurrent episodes of heat intolerance and generalized hives with mild physical exertion since the age of 20, diagnosed as cholinergic urticaria (Figure 1 - patient's back showing itchy red hives precipitated during exertion). Except for tonsillectomy at age 10, his surgical history is unremarkable. None of his siblings or either parents had similar symptoms. On examination there was symmetric $4 / 5$ weakness with hip flexion and knee extension and the rest of the neurological examination was normal. Laboratory work demonstrated a creatinine kinase level of 400U/L (normal range: 52-336U/L, Mayo Clinic). Nerve conduction studies and needle electromyography were normal. (Figure 2 and Figure 3 show the muscle biopsy obtained from patient's vastus lateralis reflecting fiber type variation on $\mathrm{H} \& \mathrm{E}$ stain and central cores with predominance of typel fibers, respectively). Next generation sequencing of RYRl gene showed a heterogeneous missense mutation- K1393R, pLys1393Arg (AAG>AGG): c4178A $>\mathrm{G}$ in exon 29 of RYRl.

He and his wife have four children: two daughters (aged 13,9 years) and two sons (fraternal twins, aged 6 years). The daughters had no significant birth history, neonatal history, or developmental delay, but eventually developed exertional heat intolerance with dancing. However, the pregnancy of the twins was complicated by polyhydramnios. The twins were hypotonic and had poor sucking at birth. They also had delay in motor milestones. Next generation sequencing of RYRl gene of all children revealed the identical heterogeneous missense mutation- K1393R, pLysl393Arg (AAG $>A G G): c 4178 A>G$ in exon 29 of RYRl gene.

\section{Discussion}

The RYRl gene encodes the principal sarcoplasmic reticulum calcium release channel (RYRl protein), with 
a crucial role in skeletal muscle excitation contraction coupling by connecting sarcoplasmic reticulum to transverse tubules. The fundamental role of RYRI in normal muscle homeostasis and functioning is reflected in the wide range of both dominant and recessive disorders associated with RYRl mutations ${ }^{1,2,3}$.

The clinical and pathological features of RYRlrelated disorders with mainly autosomal dominant (AD) inheritance - central core disease (CCD) and the malignant hypothermia syndrome (MHS) trait based on a positive in vitro contracture test (IVCT) - have been recognized for a long time. The full clinico-pathological spectrum of autosomal recessive (AR) RYRl-related myopathies has only emerged in recent years and continues to expand. More recently recognized recessive RYRl-related myopathies include forms of multi-minicore disease (MmD) with external opthalmoplegia, centronuclear myopathy (CNM) and congenital fiber type disproportion ${ }^{2}$. In addition, KingDenborough syndrome (KDS), exertional rhabdomyolysis and late-onset axial myopathy appear to be specific myopathic manifestations of malignant hyperthermia (MH)-related RYRl mutations ${ }^{3,4}$. (Figure 4 shows various phenotypic presentations with RYRl gene mutation according to previous studies).

Recent studies have also shown additional phenotypes associated with RYRl mutation including exertional myalgia, heat intolerance/illness, rhabdomyolysis, and cold-induced muscle stiffness. Muscle biopsies in these cases show only subtle changes and there is no evidence of $\mathrm{MH}$ in any of these cases $^{3}$.

Fiszer et al. reported three novel RYRl variants associated only with exertional heat illness with unrevealing muscle biopsy and no evidence of MH either in the probands or other members of the family. Interestingly they also noted two other variants which were previously reported as centronuclear myopathy but were associated only with exertional heat illness and $\mathrm{MH}$ in their cohort ${ }^{4}$.

Complete sequencing of RYRl gene has revealed variants throughout the gene. But there are particular regions and residues within the gene that are conserved (remained essentially unchanged throughout evolution), indicating unique and indispensable functional importance of their protein products. The RYRl protein has many direct, diverse protein and subunit interactions; hence it is not surprising that there is expanding range of variants both in genotypes and phenotypes ${ }^{3}$.

Taken together the above-mentioned studies and this case have shed light on the wide genotypic as well as phenotypic variability seen with RYRl mutations including varying severity of phenotypes.

\section{References}

1. M. Snoecka, B. G. M. van Engelenb, B. Kusters, M. Lammens, R. Meijerf et al., RYRl-related myopathies: a wide spectrum of phenotypes throughout life. Eur J Neurol. 2015 Jul; 22(7):1094-112. doi: 10.1111/ene.12713. Epub 2015 May 11.

2. Treves S, Jungbluth H, Muntoni F, Zorzato F. Congenital muscle disorders with cores: the ryanodine receptor calcium channel paradigm. Curr Opin Pharmacol. 2008 Jun; 8(3):319-26. doi: 10.1016/j.coph.2008.01.005. Epub 2008 Mar 4. Review. PubMed PMID: 18313359.

3. N. Dlamini, N.C. Voermans, S. Lillis, K. Stewart, EJ. Kamsteeg, G. Drost et al., Mutations in RYRl are a common cause of exertional myalgia and rhabdomyolysis. Neuromuscul Disord. 2013 Jul; 23(7):540-8. doi: 10.1016/j. nmd.2013.03.008. Epub 2013 Apr 28.

4. D Fiszer, M-A Shaw, N A. Fisher, IM. Carr, PK. Gupta et al., Next Generation Sequencing of RYRI and CACNAlS in Malignant Hyperthermia and Exertional Heat Illness. Anesthesiology 5 2015, Vol.122, 1033-1046. doi:10.1097/ ALN.0000000000000610.

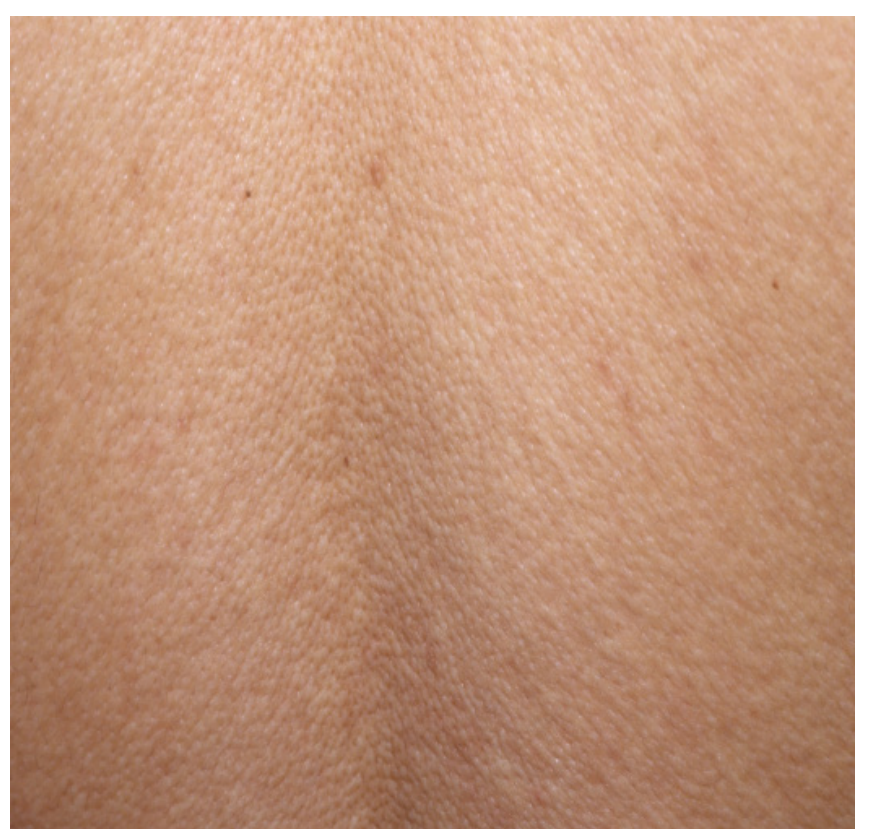

Figure 1. Back showing urticaria. 


\section{Clinic Stuff}

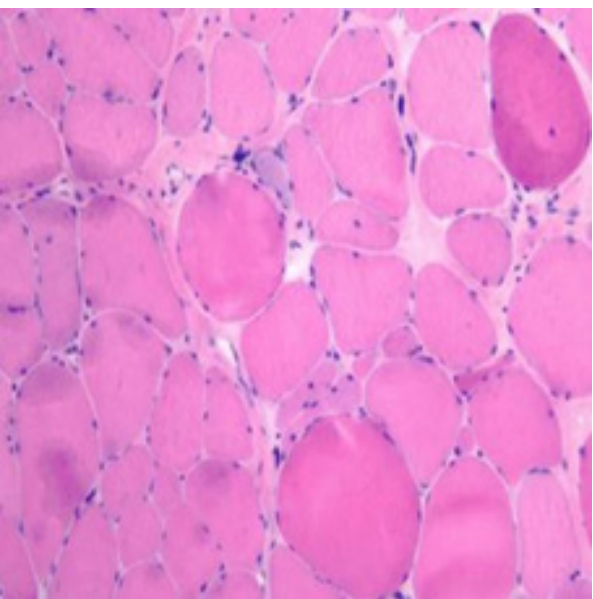

Figure 2. Vastus Lateralis biopsy with H \& E stain showed mild fiber type variation with internal nuclei and mild endomysial fibrosis.

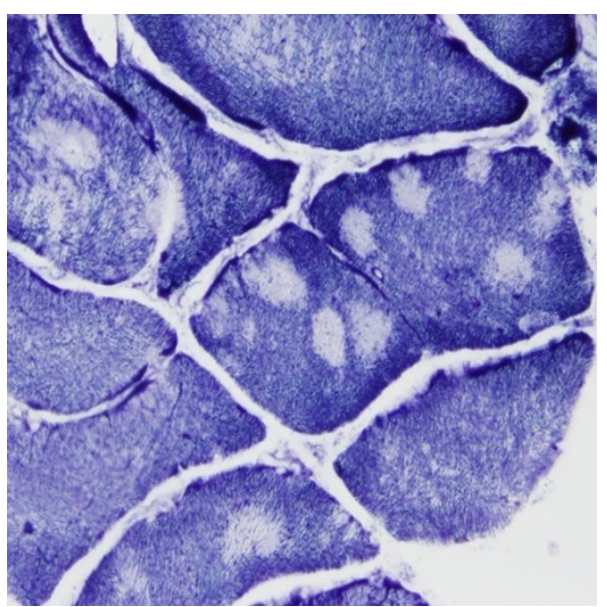

Figure 3. Vastus Lateralis biopsy with NADH stain showed multi (mini) core pattern with predominance of type 1 fibers.

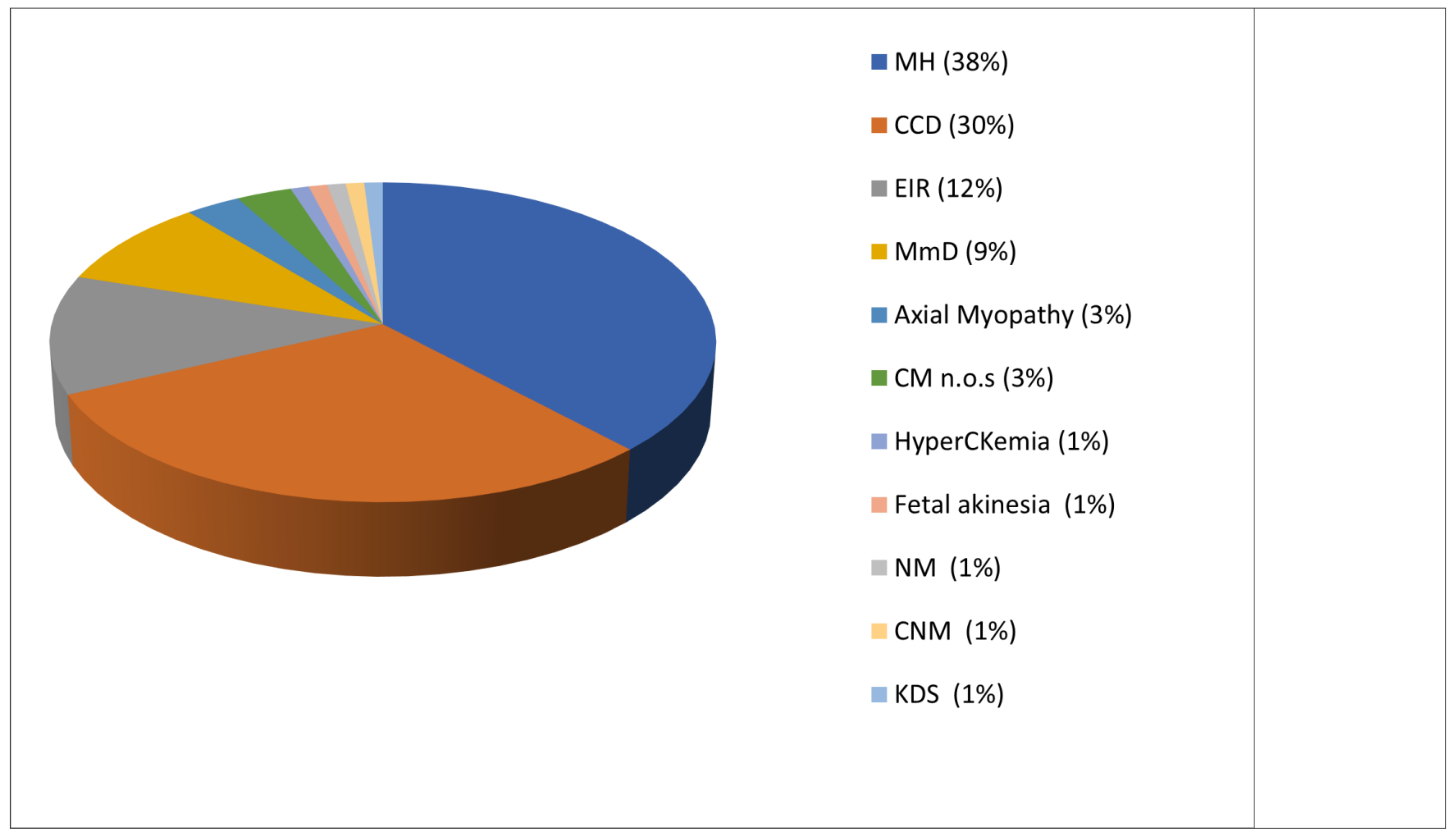

Figure 4. Various phenotypic presentations with RYRl gene mutation according to previous studies'. Abbreviations: MH, malignant hyperthermia; CCD, central core disease; EIR, exercise induced rhabdomyolysis; MmD, multiminicore disease; CM n.o.s., congenital myopathy not otherwise specified; NM, nemaline myopathy; CNM, centronuclear myopathy; KDS, King-Denborough syndrome; CK, creatinine kinase. 